\title{
Low Temperature Synthesis of Mesoporous y-Alumina supported Nickel Oxides and their Catalytic Application for $\mathrm{CO}_{2}$ Methanation
}

\author{
Xingfu Shang*, Digu Deng, Xueguang Wang*, Xiujing Zou, Weizhong Ding, \\ Xionggang Lu
}

\author{
State Key Laboratory of Advanced Special Steel, Shanghai University, Yanchang Road No.149, \\ Shanghai 200072, China
}

E-mail: xfshang@shu.edu.cn; wxg228@shu.edu.cn

\begin{abstract}
Keywords: Low temperature, mesoporous $\gamma$-alumina, Nickel catalyst, $\mathrm{CO}_{2}$ methanation Abstract. The mesoporous $\gamma$-alumina supported nickel oxides with different Ni/Al molar ratios $(x=$ $0.05,0.10,0.125,0.25,0.50)$ have been prepared by a simple partial hydrolysis of aqueous solution of $\mathrm{Al}\left(\mathrm{NO}_{3}\right)_{3}$ and $\mathrm{Ni}\left(\mathrm{NO}_{3}\right)_{2}$ with $\left(\mathrm{NH}_{4}\right)_{2} \mathrm{CO}_{3}$ without templates or organic surfactants at low calcination temperature of $400{ }^{\circ} \mathrm{C}$. The as-prepared materials possessed wormhole-like mesoporous structures with large specific surface areas of $252-477 \mathrm{~m}^{2} / \mathrm{g}$ and narrow pore size distributions in the range of 3-4 nm. The specific surface areas and pore volumes of the materials gradually decreased with the increase in the $\mathrm{Ni} / \mathrm{Al}$ molar ratio and the nickel species were highly dispersed in the materials. Among the catalysts tested for the methanation of $\mathrm{CO}_{2}$, the mesoporous $\gamma$-alumina supported nickel oxides with the $\mathrm{Ni} / \mathrm{Al}$ molar ratios of 0.25 revealed the best catalytic performance and showed the similar catalyst activity to the counterpart with ordered mesoporous alumina supported nickel oxide synthesized through templating approach.
\end{abstract}

\section{Introduction}

Due to their low cost and high activity, alumina supported nickel oxides $\left(\mathrm{NiO} / \mathrm{Al}_{2} \mathrm{O}_{3}\right)$ have been widely used as catalyst [1-3], electro chromic material [4], anodic material [5], and so on. The performance of the $\mathrm{NiO} / \mathrm{Al}_{2} \mathrm{O}_{3}$ depends not only on the nature and structure of active nickel, but also on the chemical and physical properties of $\mathrm{Al}_{2} \mathrm{O}_{3}$ supports. It has been reported that nickel species finely dispersed on the surface of high-surface-area mesoporous $\gamma$-alumina ( $\gamma$-MA) efficiently enhanced the activity and durability of the $\mathrm{NiO} / \mathrm{Al}_{2} \mathrm{O}_{3}$ materials during the various applications $[6,7]$. In order to improve the properties of mesoporous $\mathrm{NiO} / \gamma$-MA materials, many different methods such as co-precipitation [2,8], impregnation [6,9], sol-gel [10,11], etc. have been developed. Among these methods, the wet impregnation of $\gamma$-MA with inorganic nickel salt precursors is considered to be the most convenient for the $\mathrm{NiO} / \gamma$-MA materials [12]. However, this method causes the decrease in specific surface area of the $\gamma$-MA supports owing to the pore blockage and nickel oxide aggregation on the surfaces, resulting in the decrease the reaction activity during various applications. In order to overcome these disadvantages, ordered mesoporous alumina (OMA) supported nickel oxides have been synthesized with aluminum alkoxides as aluminum sources via one-pot templating approach $[13,14]$. The obtained nickel species are homogeneously dispersed on the mesoporous alumina supports, and showed better catalytic activity and stronger resistance toward catalyst deactivation due to the high nickel dispersion and the "confinement effect" of the mesoporous structure, compared with the counterparts through conventional impregnation method. However, the mesoporous alumina supports obtained via the templating approach give only amorphous framework walls below $700{ }^{\circ} \mathrm{C}$, which lack the structure stability and surface characteristics of $\gamma$-alumina for various applications, while higher temperature calcinations for $\gamma$-alumina phase result in drastic deterioration of texture properties and the formation of nickel aluminate spinel phase, in which Ni species are embedded in the lattice of the $\gamma$-alumina and are difficult to be reduced to active metal nickel atoms $[15,16]$. Therefore, there is still a great deal of interest in developing one step approach to fabricate stable high-surface-area $\mathrm{NiO} / \gamma$-MA materials with both natures of crystalline $\gamma$-alumina and highly dispersed nickel species at lower temperatures. 
Recently, we have reported that $\mathrm{NH}_{4} \mathrm{NO}_{3}$ and $\mathrm{Al}$ species hybrid with $\mathrm{Al}_{13}$ cations $\left[\mathrm{AlO}_{4} \mathrm{Al}_{12}(\mathrm{OH})_{24}\left(\mathrm{H}_{2} \mathrm{O}\right)_{12}\right]^{7+}$ of Keggin structure could be obtained by a non-surfactant sol-gel method, and all $\mathrm{Al}$ species were almost transformed into mesoporous crystalline $\gamma$-alumina with high surface area $\left(>380 \mathrm{~m}^{2} / \mathrm{g}\right)$, large pore volume $\left(\sim 0.3 \mathrm{~cm}^{3} / \mathrm{g}\right)$ and narrow pore size distribution peaked at $\sim 3.9$ $\mathrm{nm}$ at a low temperature of $200{ }^{\circ} \mathrm{C}[17,18]$. The study stimulated us to extend this approach to the mesoporous $\gamma$-alumina supported nickel oxides. In this work, a series of the mesoporous $\gamma$-alumina supported nickel oxides $(x \mathrm{NiO} / \gamma-\mathrm{MA})$ with various $\mathrm{Ni} / \mathrm{Al}$ molar ratios were prepared by a single-step co-hydrolysis method at low calcination temperature of $400{ }^{\circ} \mathrm{C}$. The effect of Ni/Al molar ratio of the $x \mathrm{NiO} / \gamma$-MA materials on the physicochemical properties and catalytic activities in the methanation of carbon dioxide were investigated. The ordered mesoporous alumina (OMA) supported nickel oxide with the $\mathrm{Ni} / \mathrm{Al}$ molar ratio of $0.25(0.25 \mathrm{NiO} / \mathrm{OMA})$ was prepared via the templating approach according to the reference [13] for catalytic activity comparison.

\section{Experimental section}

2.1. Preparation of $\boldsymbol{\gamma}$-MA-supported Ni oxides. All reagents were analytical-grade, purchased from Sinopharm Chemical Reagent Co., Ltd. and used as received without purification. The $x \mathrm{NiO} / \gamma-\mathrm{MA}$ materials with different $\mathrm{Ni} / \mathrm{Al}$ molar ratios $(x=0,0.05,0.10,0.125,0.25$, and 0.5$)$ were prepared via co-hydrolysis of an aqueous solution of $\mathrm{Al}\left(\mathrm{NO}_{3}\right)_{3} \cdot 9 \mathrm{H}_{2} \mathrm{O}$ and $\mathrm{Ni}\left(\mathrm{NO}_{3}\right)_{2} \cdot 6 \mathrm{H}_{2} \mathrm{O}$ precursors with $\left(\mathrm{NH}_{4}\right)_{2} \mathrm{CO}_{3}$ solution as hydrolyser as described previously with minor modification $[17,18] .50 \mathrm{ml}$ of the metal nitrate solution with a total $[\mathrm{Ni}+\mathrm{Al}]$ ion concentration of $2.0 \mathrm{~mol} / 1$ was heated to $70{ }^{\circ} \mathrm{C} .1$ $\mathrm{mol} / \mathrm{L}\left(\mathrm{NH}_{4}\right)_{2} \mathrm{CO}_{3}$ aqueous solution was dropped very slowly $(\sim 0.9 \mathrm{~mL} / \mathrm{min})$ into the above aqueous solution of inorganic salts with vigorous magnetic stirring using a syringe pump until a sudden formation of monolithic transparent gel occurred and the stirring was stopped. At this moment the $\mathrm{pH}$ value of the gel was measured in the range of 5.2-5.8, slightly varying with the Ni/Al molar ratios. The gel beaker was covered with plastic film and aged at $30^{\circ} \mathrm{C}$ for $48 \mathrm{~h}$. After this, the crude gel was taken out and dispersed in an open glass dish at $100{ }^{\circ} \mathrm{C}$ for $24 \mathrm{~h}$. Then the as-prepared solid was treated at $200{ }^{\circ} \mathrm{C}$ for $10 \mathrm{~h}$, and finally further calcined at $400{ }^{\circ} \mathrm{C}$ for $10 \mathrm{~h}$ in air (Caution! This process must be done cautiously in order to avoid the explosion of ammonium nitrate). For comparison, the amorphous ordered mesoporous alumina (OMA) supported nickel oxides with the Ni/Al molar ratio of 0.25 (denoted as $0.25 \mathrm{NiO} / \mathrm{OMA}$ ) was prepared via the surfactant-assisted route according to the document [13].

2.2. Characterization techniques. Powder $X$-ray diffraction (XRD) of the samples were performed with a Rigaku D/MAX-2200 apparatus using CuK $\alpha$ radiation $(\lambda=0.15418 \mathrm{~nm})$ operated at a voltage of $40 \mathrm{kV}$ and a current of $40 \mathrm{~mA}$. Transmission electron microscopy (TEM) images were obtained with a JEM-2010F microscope. The sample was prepared by placing a drop of the ethanol solution of a well-ground materials powder onto a carbon-coated copper grid (300 mesh) followed by evaporation of the ethanol.

$\mathrm{N}_{2}$ adsorption and desorption isotherms were measured using a Micromeritics ASAP 2020 analyzer at $-196{ }^{\circ} \mathrm{C}$. Before the measurement, each sample was degassed at $300{ }^{\circ} \mathrm{C}$ for $6 \mathrm{~h}$. The specific surface areas were evaluated using the Brunauer-Emmett-Teller method in the $\mathrm{P} / \mathrm{P}_{0}$ range from 0.05 to 0.25 . The pore size distribution curves were calculated using the desorption branch of the isotherms and the Barrett-Joyner-Halenda method. The pore volumes were estimated from the adsorbed amount at $P / P_{0}=0.995$.

Temperature-programmed reduction with $\mathrm{H}_{2}\left(\mathrm{H}_{2}\right.$-TPR) was performed on a homemade equipment. Prior to the measurement, $0.1 \mathrm{~g}$ of sample placed in a quartz reactor was first pretreated in an $\mathrm{Ar}$ stream at $200{ }^{\circ} \mathrm{C}$ for $0.5 \mathrm{~h}$. After this pretreatment, $\mathrm{H}_{2}$-TPR was conducted with a gas mixture of 5 vol. $\% \mathrm{H}_{2}$ in Ar at $30 \mathrm{~mL} / \mathrm{min}$. The temperature was raised to $1000{ }^{\circ} \mathrm{C}$ at a heating rate of $10{ }^{\circ} \mathrm{C} / \mathrm{min}$. The amount of $\mathrm{H}_{2}$ uptake was measured with a thermal conductivity detector.

2.3. Catalytic activity measurements. The methanation of carbon dioxide over the $x \mathrm{NiO} / \gamma-\mathrm{MA}$ catalysts and the $0.25 \mathrm{NiO} / \mathrm{OMA}$ catalyst was carried out under atmospheric pressure in a continuous flow fixed-bed quartz tube reactor with an internal diameter of $10 \mathrm{~mm}$. The reaction gases $\left(\mathrm{H}_{2}, \mathrm{CO}_{2}\right)$ 
were controlled using the mass flow controllers. The temperature was monitored using a thermocouple placed in the middle of the catalyst bed. A sample of $0.1 \mathrm{~g}$ of catalyst (40 to $60 \mathrm{mesh}$ ) mixed with $0.8 \mathrm{~g}$ of quartz particles with similar sizes (40 to 60 mesh) was placed at the middle portion of the reactor. Prior to the reaction, the catalyst was reduced in situ by a flow of $\mathrm{H}_{2}(40$ $\mathrm{mL} / \mathrm{min}$ ) at the temperature of $600{ }^{\circ} \mathrm{C}$ for $1 \mathrm{~h}$, then the reaction gases using a mixture of carbon dioxide and hydrogen at a ratio of $\mathrm{CO}_{2}: \mathrm{H}_{2}=1: 4$ was introduced into the reactor in the proper reaction temperature range of $200-500{ }^{\circ} \mathrm{C}$ in steps of $50{ }^{\circ} \mathrm{C}$ and at a gas hourly space velocity (SV) of inlet gas of $6000 \mathrm{mLg}^{-1} \mathrm{~h}^{-1}$ (STP). After the $2 \mathrm{~h}$ reaction at each time, the system became stable and the effluent gas was dried and then analyzed using an on-line GC-TCD gas chromatograph with a packed sieve column for $\mathrm{CH}_{4}, \mathrm{CO}$ and a Porapak Q column for $\mathrm{CO}_{2}$. The value of $\mathrm{CO}_{2}$ conversion $\left(\mathrm{Xco}_{2}\right)$ and $\mathrm{CH}_{4}$ selectivity $\left(\mathrm{S}_{\mathrm{CH} 4}\right)$ were obtained using the following equations:

$$
\begin{aligned}
& \mathrm{XCO}_{2}=\left(\frac{\mathrm{CO}}{\mathrm{CH}_{4}+\mathrm{CO}+\mathrm{CO}_{2}}\right) \times 100 \% \\
& S_{\mathrm{CH}_{4}}=\left(\frac{\mathrm{CH}_{4}}{\mathrm{CH}_{4}+\mathrm{CO}}\right) \times 100 \%
\end{aligned}
$$

\section{Results and discussion}

3.1 XRD analyses. XRD was used to study the crystalline phases of the prepared materials. The XRD patterns of the $x \mathrm{NiO} / \gamma$-MA $(x=0.05,0.10,0.125,0.25$ and 0.5$)$ materials and pure $\gamma$-MA support are presented in Fig.1. Similar to $\gamma$-MA, all the $x \mathrm{NiO} / \gamma$-MA materials showed three diffraction peaks around $2 \theta=37^{\circ}, 45^{\circ}, 66^{\circ}$, corresponding to the (311), (400) and (440) reflections for spinel, which indicated that aluminum hydroxides and oxyhydroxides in the gel were transformed to $\gamma$-alumina or $\mathrm{NiAl}_{2} \mathrm{O}_{4}$ spinel. Regardless of $\mathrm{Ni} / \mathrm{Al}$ molar ratio, no characteristic peaks corresponding to nickel oxides were observed, suggesting that nickel species were highly dispersed with very small particle sizes below the detection limit of XRD measurements, or reacted with alumina to form $\mathrm{NiAl}_{2} \mathrm{O}_{4}$ in the $x \mathrm{NiO} / \gamma$-MA matrices [19]. It was observed that the reflections from (440) and (400) planes shifted to lower $2 \theta$ angles with increasing $\mathrm{Ni} / \mathrm{Al}$ molar ratios. This result demonstrated that $\mathrm{Ni}^{2+}$ ions could diffuse into the structure of $\gamma$-MA at calcination temperature of $400{ }^{\circ} \mathrm{C}$ to a certain extent, likely due to homogeneous mixing and strong interaction between alumina and $\mathrm{Ni}^{2+}$ ions during the preparation, which caused the expansion of crystalline lattice of $\gamma$-alumina due to the incorporation of larger nickel ions $[8,20]$.

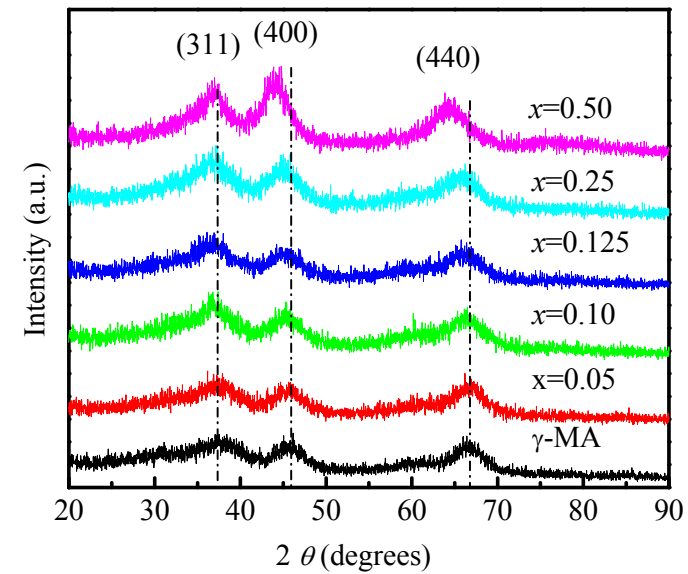

Fig. 1. XRD patterns of pure $\gamma$-MA and the $\mathrm{xNiO} / \gamma$-MA samples

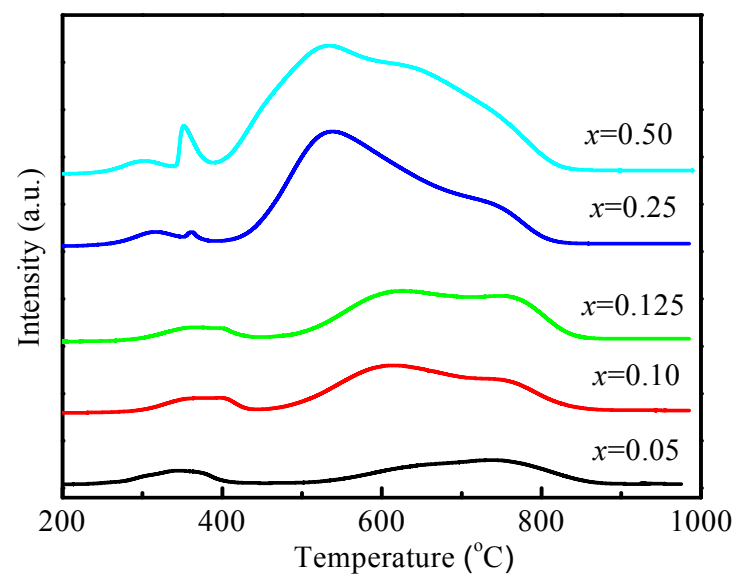

Fig. 2. TPR profiles of the $\mathrm{xNiO} / \gamma$-MA materials

3.2 $\mathbf{H}_{2}-$ TPR analyses. The TPR profiles in Fig. 2 were used to investigate the nickel species, reducibility, and interaction between nickel species and alumina in the $x \mathrm{NiO} / \gamma$-MA materials. It could 
be seen that there were different nickel species in the samples. The weak reduction peaks within a lower temperature range of $300-450{ }^{\circ} \mathrm{C}$ could be attributed to the reduction of amorphous $\mathrm{NiO}$ or free crystalline $\mathrm{NiO}$ phase beyond the detection limit of XRD [21]. The broad $\mathrm{H}_{2}$ consumption peak in the temperature range of 450 to $850{ }^{\circ} \mathrm{C}$ could be divided into two reduction bands. The former was assigned to the reduction of highly dispersed $\mathrm{NiO}$ species on the support surface, which had a strong interaction with the support; and the latter was related to the reduction of surface nickel aluminate-like species [7,22]. With the increase of $\mathrm{Ni} / \mathrm{Al}$ molar ratio in the $x \mathrm{NiO} / \gamma$-MA materials, the reduction peaks shifted to lower temperatures due to the decrease in the interaction between nickel species and alumina support [21,22]. The peak area of the reduction of highly dispersed NiO species increased with increasing $\mathrm{Ni} / \mathrm{Al}$ molar ratio. When $\mathrm{Ni} / \mathrm{Al}$ molar ratio was enhanced to 0.10 , the highly dispersed $\mathrm{NiO}$ species was predominant in the $0.1 \mathrm{NiO} / \gamma-\mathrm{MA}$ materials. For the $0.25 \mathrm{NiO} / \gamma-\mathrm{MA}$ materials, the peak area of the reduction of highly dispersed NiO species is significantly larger than that of the $0.125 \mathrm{NiO} / \gamma-\mathrm{MA}$. These results implied that highly dispersed $\mathrm{NiO}$ species on the support surface were preferentially formed with increasing $\mathrm{Ni} / \mathrm{Al}$ molar ratios in the $x \mathrm{NiO} / \gamma$-MA materials.

Table 1. Textural properties of the $\mathrm{xNiO} / \gamma$-MA samples samples

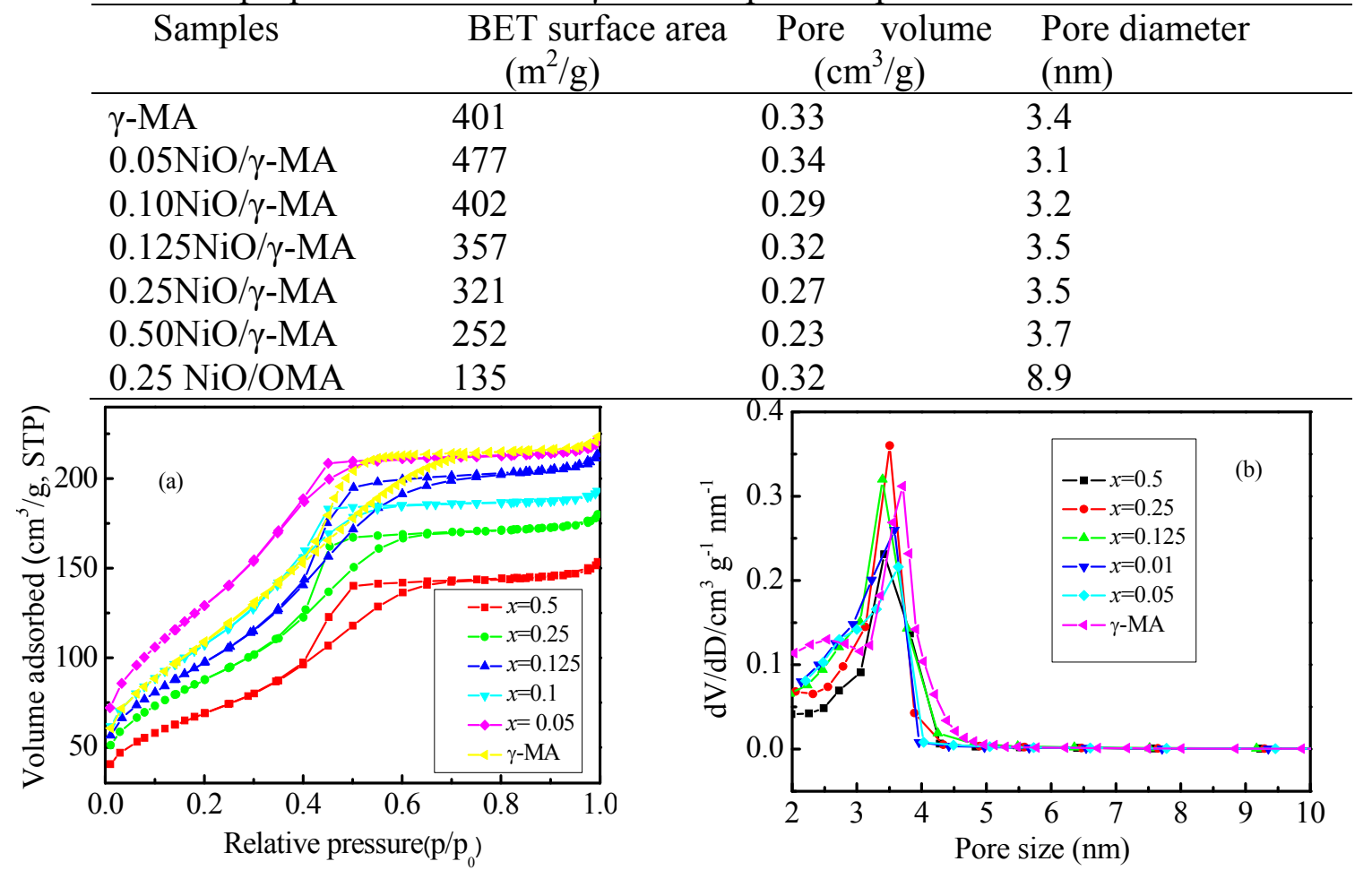

Fig. 3. (a) $\mathrm{N}_{2}$ adsorption-desorption isotherms and (b) BJH pore size distributions of the $x \mathrm{NiO} / \gamma-\mathrm{MA}$ materials

3.3 Textural properties of the $x \mathbf{N i O} / \gamma-$ MA. Fig. $3(\mathrm{a})$ and (b) displayed the $\mathrm{N}_{2}$ adsorption-desorption isotherms and pore size distribution curves of the pure $\gamma$-MA support and $x \mathrm{NiO} / \gamma$-MA materials, respectively. Similar to the $\gamma$-MA, all the $x \mathrm{NiO} / \gamma$-MA materials calcined at $400{ }^{\circ} \mathrm{C}$ exhibited characteristic type IV isotherms with apparent hysteresis loops, which were typical of mesoporous materials according to the IUPAC classification. The adsorption-desorption hystereses took place within the $P / P_{0}$ range of $0.40-0.65$, demonstrating that the as-prepared $x \mathrm{NiO} / \gamma$-MA materials contained mesopores with relatively uniform pore sizes, which were in accordance with the observations in the TEM images of Fig. 4. These results demonstrated that the addition of nickel ions in the gel did not change mesoporous structure of $\gamma$-MA. Table 1 summarized the physical properties of pure $\gamma$-MA support and $x \mathrm{NiO} / \gamma$-MA materials. It could been seen that the $x \mathrm{NiO} / \gamma$-MA materials possessed large specific surface areas of $252-477 \mathrm{~m}^{2} / \mathrm{g}$, pore volumes of $0.23-0.34 \mathrm{~cm}^{3} / \mathrm{g}$, and pore sizes of $3.1-3.7 \mathrm{~nm}$. Generally, specific surface areas and pore volumes gradually decreased with the increase in the $\mathrm{Ni} / \mathrm{Al}$ molar ratio. For example, the $0.05 \mathrm{NiO} / \gamma-\mathrm{MA}$ sample showed a specific surface area of $477 \mathrm{~m}^{2} / \mathrm{g}$, a pore volume of $0.34 \mathrm{~cm}^{3} / \mathrm{g}$ and a pore size of 3.1 
$\mathrm{nm}$, whereas those of the $0.5 \mathrm{NiO} / \gamma$-MA were $252 \mathrm{~m}^{2} / \mathrm{g}, 0.23 \mathrm{~cm}^{3} / \mathrm{g}$ and $3.7 \mathrm{~nm}$, respectively. The $0.25 \mathrm{NiO} / \mathrm{OMA}$ sample prepared by the surfactant-assisted method showed a specific surface area of $135 \mathrm{~m}^{2} / \mathrm{g}$, a pore volume of $0.32 \mathrm{~cm}^{3} / \mathrm{g}$ and a pore size of $8.9 \mathrm{~nm}$.

3.4 TEM analysis. The TEM images of respective $x \mathrm{NiO} / \gamma-\mathrm{MA}(x=0.05,0.25$ and 0.5$)$ materials were shown in Fig. 4. For comparison, the TEM image of mesoporous $\gamma$-alumina was also presented. It could be seen that the $x \mathrm{NiO} / \gamma$-MA materials showed homogenously wormhole-like mesoporous structures with a pore diameter of ca. $4 \mathrm{~nm}$, which were almost the same as that of pure $\gamma$-MA support [18]. No visible evidence representing nickel agglomerates were found in these samples. These results further confirmed that nickel species were highly dispersed in the $x \mathrm{NiO} / \gamma-\mathrm{MA}$ materials, which was in good agreement with the XRD results in Fig.1.

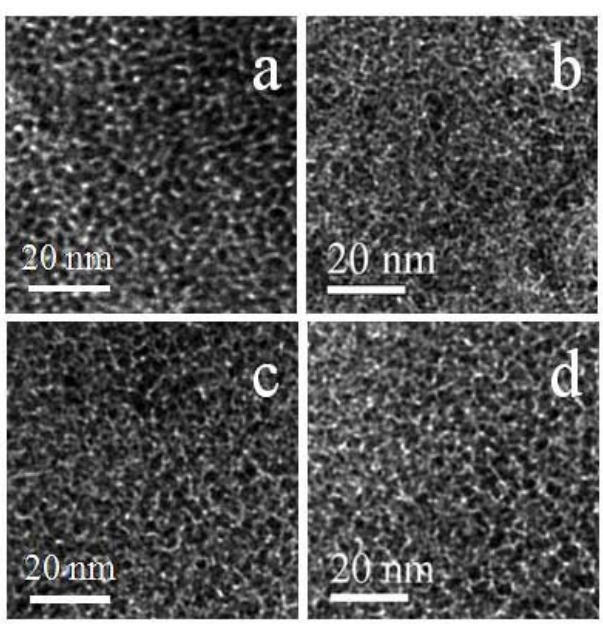

Fig. 4. TEM images of the as-prepared samples (a) $\gamma$-MA, (b) $0.05 \mathrm{NiO} / \gamma-\mathrm{MA}$, (c) $0.25 \mathrm{NiO} / \gamma-\mathrm{MA}$, (d) $0.50 \mathrm{NiO} / \gamma-\mathrm{MA}$

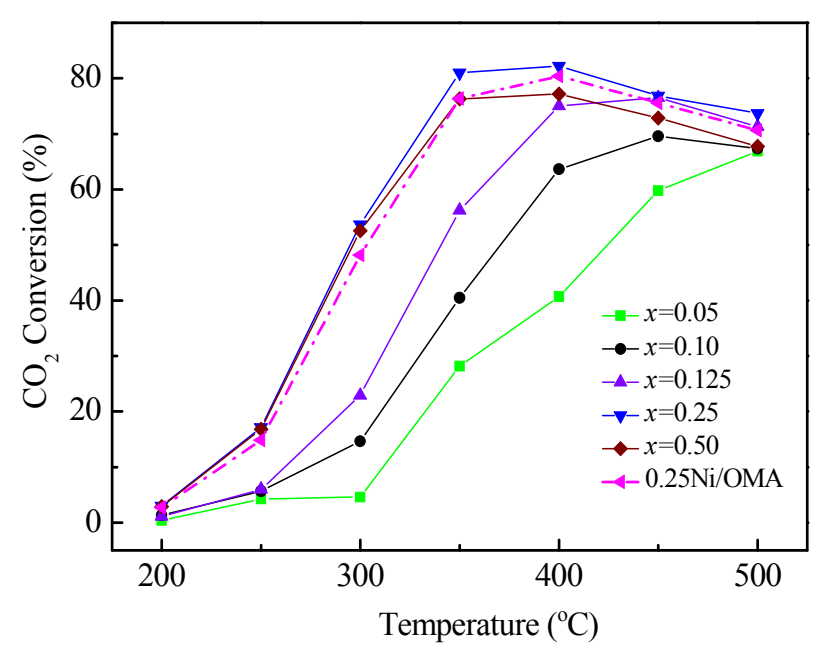

Fig. 5. The performance of $\mathrm{xNiO} / \gamma-\mathrm{MA}$ and $0.25 \mathrm{NiO} / \mathrm{OMA}$ catalysts for methanation of carbon dioxide. Reaction condition:

3.5 Catalytic performances of the methanation of $\mathrm{CO}_{2}$. To evaluate the catalytic performances of the as-prepared materials, the as-prepared $x \mathrm{NiO} / \gamma$-MA materials and the comparative $0.25 \mathrm{NiO} / \mathrm{OMA}$ material were used as catalysts for the methanation of $\mathrm{CO}_{2}$. The $\mathrm{CO}_{2}$ conversions as a function of reaction temperature were presented in Fig. 5. It could be seen that the $\mathrm{Ni} / \mathrm{Al}$ molar ratios of the catalysts and the reaction temperature had significant influence on the catalyst activity. At all temperatures, the $0.25 \mathrm{NiO} / \gamma$-MA catalyst exhibited the best catalytic activity in all the catalysts. At $400{ }^{\circ} \mathrm{C}$, the highest $\mathrm{CO}_{2}$ conversion of $84 \%$ over the $0.25 \mathrm{NiO} / \gamma$-MA catalyst is close to corresponding equilibrium values. As we know, the intermediate of $\mathrm{CO}_{2}$ methanation is $\mathrm{CO}$, and the reaction of $\mathrm{CO}$ production is known as reverse water gas shift reaction ( $R$ WGS reaction, $\mathrm{CO}_{2}+\mathrm{H}_{2} \rightarrow \mathrm{CO}+\mathrm{H}_{2} \mathrm{O}$ ). The following $\mathrm{CO}$ methanation $\left(\mathrm{CO}+3 \mathrm{H}_{2} \rightarrow \mathrm{CH}_{4}+\mathrm{H}_{2} \mathrm{O}\right.$ ) is of exothermic nature, and thus lower reaction temperature is favored for higher $\mathrm{CH}_{4}$ selectivity [23]. As for $x \mathrm{NiO} / \gamma-\mathrm{MA}$ and $0.25 \mathrm{NiO} / \mathrm{OMA}$, almost no $\mathrm{CO}$ was detected at the reactor outlet in the temperature range between 250 and $400{ }^{\circ} \mathrm{C}$, and thus $\mathrm{CH}_{4}$ selectivity was close to 1 at low temperatures. The reaction temperature was further increased, the $\mathrm{CO}_{2}$ conversion and $\mathrm{CH}_{4}$ selectivity started to decline, because $\mathrm{CO}_{2}$ is converted into $\mathrm{CO}$ on $\mathrm{Ni}$ surface (RWGS reaction)[24]. With elevating the reaction temperature from $400{ }^{\circ} \mathrm{C}$ to $500{ }^{\circ} \mathrm{C}$, the $\mathrm{CO}_{2}$ conversion of the $0.25 \mathrm{NiO} / \gamma$-MA catalyst decreased from $82.2 \%$ to $73.7 \%$, whereas that of the comparative $0.25 \mathrm{NiO} / \mathrm{OMA}$ catalyst decreased from $80.4 \%$ to $70.6 \%$. The $\mathrm{CH}_{4}$ selectivity of all the catalysts were more than $99.5 \%$ at all temperature. The results demonstrated that the crystalline $\gamma$-alumina with wormhole-like mesostructures supported nickel oxides showed similar catalytic activity to ordered mesoporous alumina suppoted nickel oxides because the wormhole-like three-dimensional mesostructures enhanced accessibility of the active sites by reactant molecules $[14,25]$. 


\section{Conclusions}

The mesoporous $\gamma$-alumina supported nickel oxides with different $\mathrm{Ni} / \mathrm{Al}$ molar ratios were synthesized by co-hydrolysis method without any templating agents and surfactants at low calcination temperature of $400{ }^{\circ} \mathrm{C}$. The as-prepared $x \mathrm{NiO} / \gamma$-MA materials showed similar porous structures to pure mesoporous $\gamma$-alumina, with large specific surface areas of $252-477 \mathrm{~m}^{2} / \mathrm{g}$ and narrow pore size distributions in the range of 3-4 $\mathrm{nm}$. The specific surface areas and pore volumes of $x \mathrm{NiO} / \gamma$-MA gradually decreased with the increase of the $\mathrm{Ni} / \mathrm{Al}$ molar ratio. The XRD and TEM results demonstrated the nickel species were finely dispersed in the $x \mathrm{NiO} / \gamma-\mathrm{MA}$ materials. The results of the methanation of $\mathrm{CO}_{2}$ demonstrated that the $0.25 \mathrm{NiO} / \gamma-\mathrm{MA}$ material had best catalytic performance and showed the similar catalyst activity to the counterpart with ordered mesoporous alumina supported nickel oxide. It can be expected that the mesoporous $\gamma$-alumina supported metal oxides prepared at low temperatures possess more excellent properties, and are more adjustable in surface areas and surface properties to satisfy various potential applications in a variety of industrial processes.

\section{Acknowledgements}

This research was financially supported by Innovation Program of Shanghai Municipal Education Commission (No.14ZZ100), Innovation Fund of Shanghai University and The Program of Shanghai Young College Teachers Training of Shanghai Municipal Education Commission.

\section{References}

[1] P. Manidipa, P. Nabanita and B. Asim: Eur. J. Inorg. Chem. 32 (2010),5129.

[2] Y.S. Seo, Y.S. Jung and W.L.Yoon : Int. J. Hydrogen Energy 36 ( 2011), 94.

[3] S. K.Yadav and P. J. Jeevanandam: J.Alloys Compd. 610 (2014),567.

[4] E. Avendaño, A. Azens and G. Niklasson: Sol. Energy Mater. Sol. Cells 84 (2004), 337.

[5] J.J. Vijaya, L.J. Kennedy and G. Sekaran: Mater. Lett. 61 (2007),5213.

[6] J.G. Seo, M.H. Youn and S. Park: J. Power Sources 186 (2009),178.

[7] J.G. Seo, M.H. Youn and I.K. Song: Int. J. Hydrogen Energy 34 (2009),1809.

[8] G.H. Li, L.J. Hu and J.M. Hill, Appl. Catal. A 301 (2006),16.

[9] P. Daeil, J.M. Dong and K. Taegyu:Fuel Process.Technol. 112 (2013), 28.

[10] H.A. Mohamad, M. Kshudiram and N. Jarrod: Appl. Catal. B 119-120 (2012),217.

[11] Y. Bang, J.G. Seo and M.H. Youn: Int. J. Hydrogen Energy 37 (2012),1436.

[12] H.S. Roh, K.W. Jun and S.E. Park:Appl. Catal. A 251 (2003),275.

[13] S.M. Morris, P.F. Fulvio and M. Jarociec: J. Am. Chem. Soc.130 (2008),15210.

[14] N.Wang, K. Shen and L.H. Huang: ACS Catal. 3 (2013),1638.

[15] Z.Y. Hou and T. Yashima:Appl. Catal. A 261 (2004),205.

[16] R.C. Yang, J.S. Wu and X.G. Li: Appl. Catal. A 383 (2010),112.

[17] X.F. Shang, X.G. Wang and W.X. Nie: Mater. Lett. 83 (2012),91.

[18] X.F. Shang, X.G. Wang and W.X. Nie: J. Mater. Chem.22 (2012),23806.

[19] J.G. Seo, M.H. Youn and I.K. Song:Catal. Surv. Asia 14 (2010),1.

[20] P. Kim, Y. Kim and H. Kim:J. Mol. Catal. A Chem. 231 (2005), 247. 
[21] R.C. Yang, X.G. Li and J.S. Wu: Appl. Catal. A 368 (2009),105.

[22] H.H. Lu, H.B. Yin and Y.M. Liu: Catal. Commun.10 (2008), 313.

[23] S. Tada, T. Shimizun and H. Kameyama: Int. J. Hydrogen Energy 37 (2012), 5527.

[24] D.C.D. da Silva, S. Letichevsky and L.E.P. Borges: Int. J. Hydrogen Energy 37 (2012) ,8923.

[25] G. Z. Wang, L. Zhang and H. X. Dai: Inorg. Chem. 47 (2008),4015. 